\title{
Death due to Ascariasis - A case report
}

\author{
Purabi Mohanty \\ Joint Director, Capital Hospital, Bhubaneswar, Odisha \\ Email: 12purabimohanty@gmail.com
}

\begin{abstract}
Ascariasis Lumbricoides (Round worm) is the largest nematode known to humans, reaching upto a length of $40 \mathrm{cms}$. Infection occurs by feco-oral route. Most of the individuals have low worm burdens and are asymptomatic, but in heavy infestation it can cause intestinal obstruction and in rare cases adult worm can obstruct common bile duct causing cholangitis or obstruct respiratory passage causing suffocation with grave consequences. We report a case, where autopsy was done on a 45 year old female who was mentally unsound and staying in a destitute home, died within hours of complaint of abdominal pain and breathlessness. Important features of autopsy were signs of Asphyxia, Jaundice and on dissection large number of adult worms were found in her stomach, oesophagus, trachea, larynx and in bile duct.

In this topic, along with case report, we discuss the life style of round worm, their clinical features and the diagnosis. We describe the possible preventive measures which includes hygienic living, community health education and provision of safe drinking water, etc. The drug treatment for round-worm infestation is also discussed in this topic.
\end{abstract}

Keywords Ascariasis Lumbricoides (Round worm), Life cycle, Intestinal obstruction, Cholangitis, suffocation, preventive measures.

\section{Introduction}

The life cycle of parasite worms are complex, alternate between sexual reproduction in the definitive host and asexual multiplication in the intermediate host depending on parasitic species. Human harbours adult worms Ascariasis Lumbricoides (round worm) which is most common Nematode infecting over billions of individuals. About one billion (807 - 1121 million) people are infected worldwide annually with about 12 million cases and 20,000 or more death. ${ }^{(7)}$

Round worm infection is most common in developing countries, is also seen in other parts of world. Adult female worm measures about $20-35 \mathrm{cms}$ and male is $12-30 \mathrm{cms}$ long. They live in the small intestine especially in Jejunal lumen. An adult worm lives for a year. Their egg production is very high, i.e. egg production is $240,000 /$ day. ${ }^{(5)}$

The route infection is oral. The ascariasis eggs are highly resistant to environmental stress and remain infective for 2-3 weeks.

\section{Lifecycle}

After a infective egg is swallowed by humans, the larva is hatched in intestine and from the intestine, it burrows through intestinal mucosa, to the liver by portal circulation, resides for 3-4 days in the liver then via right heart enters into pulmonary circulation (Jejunum-Liver-Large intestine). In the lungs, it moults twice $\left(5^{\text {th }}-10^{\text {th }}\right.$ day) reaches the lung alveoli, then to bronchi, ${ }^{(8,9)}$ trachea, larynx \& then to pharynx then swallowed on $25^{\text {th }}-29^{\text {th }}$ day. In jejunum, another moulting occurs, then turn to adult worm.

\section{Symptoms}

In the lung, phase of larval $x$-ray curt may show pneumonitis (Loffler's Syndrome). The infected person may develop fever, cough, dyspnea and utricaria and bloody sputum. ${ }^{(5,8)}$ In general circulation may settle in brain, heart, kidneys and spinal cord during larval phase. ${ }^{(8)}$

Adult worm mass can produce mechanical obstruction causing intussusceptions, volvulus and intestinal obstruction, which is common in small children. Ectopic Ascariasis (Wander Lust) ${ }^{(7)}$ can cause appendicitis, obstructive jaundice, ${ }^{(2,3)}$ Haemorghic Pancreatitis, Liver abscess and suffocation and asphyxia when worms migrate to the respiratory tract. ${ }^{(9)}$ Intestinal obstruction, b Cholanitis and foreign body obstruction of respiratory passage often are causes sudden death. ${ }^{(1,6)}$

\section{Diagnosis}

1. Microscopic detection of eggs in faecal sample.

2. Occasionally an adult worm posses in faeces.

3. During pheumonitis larva may be detected in sputum.

4. Large worms detected by contrast study of gastro intestinal back.

5. In ultasonography a tubular filling is detected.

\section{Treatment}

1. The current choice of drugs for Ascariasis infestation in the Indian Sub-continent is Mebendazole (100mg twice/day for 3 days) irrespective of patient's age, Albendazole (400 mg single dose for adults, $200 \mathrm{mg}$ in children) and Pyrantel palmoate (single dose $10 \mathrm{mg} / \mathrm{kg}$ of body weight) and second line of drug is Piperazine, Levamisole, Invermerline. ${ }^{(11)}$

2. By ultrasound endoscopic retrograde cholargio pancreatography can be used to extract biliary ascariasis worms. 
3. Surgical Treatment: Occasionally, operative intervention is required i.e., Laproscopic cholcystectomy.

\section{Case History \& Autopsy}

A 45 year old mentally unsound female, who was staying in a destitute home since last one year died suddenly within hours of symptom of abdominal pain, breathlessness and the dead body was brought for autopsy. It was accompanied by the authorities of the destitute home who cited a history of anorexia since 2 days and developing pain in the morning, and while being shifted to the Government hospital which is 10 $\mathrm{km}$ away, she vomited once, and was received dead in the hospital. Autopsy was done in the Capital Hospital, Bhubaneswar, Odisha (Govt. Hospital), the biggest peripheral hospital of the state where more than 1200 Medicolegal autopsies are conducted per year.

On Autopsy: The deceased was very thin built, average height, sunken eyes, malnourished look. The conjunctiva was yellow, nail beds and lips were blue (Picture 2). Adult round worm were coming out of nose and half open mouth(Picture 1).

\section{Picture 1}

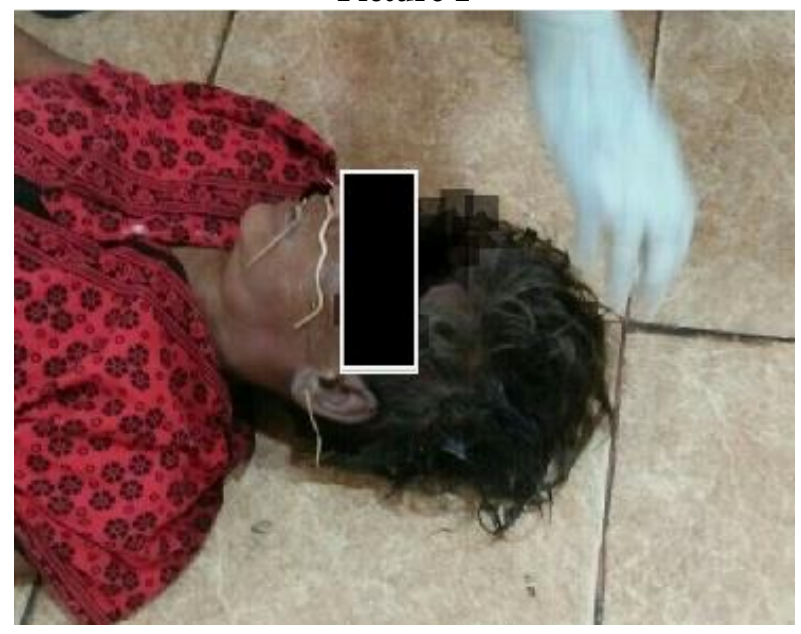

Picture 2

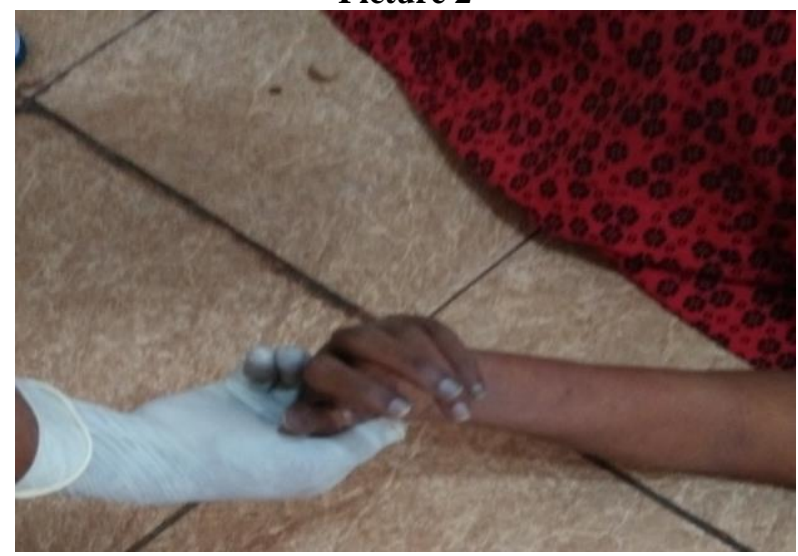

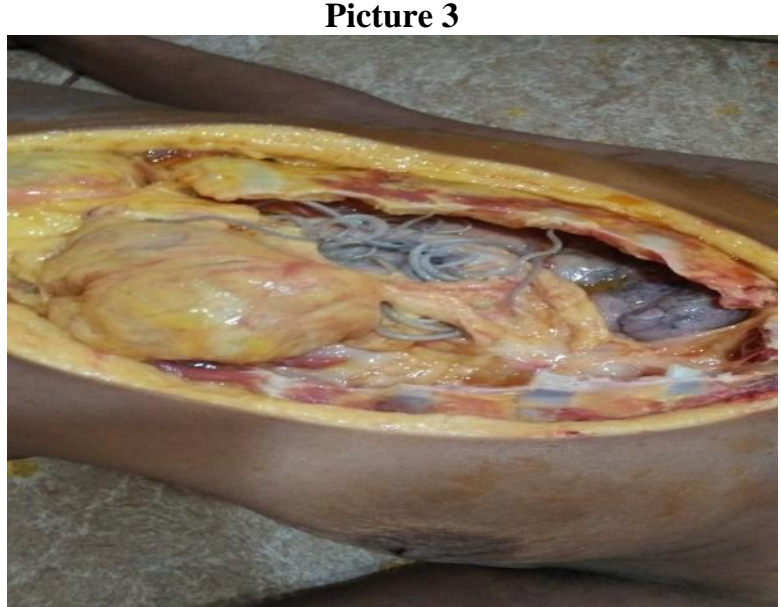

Picture 4

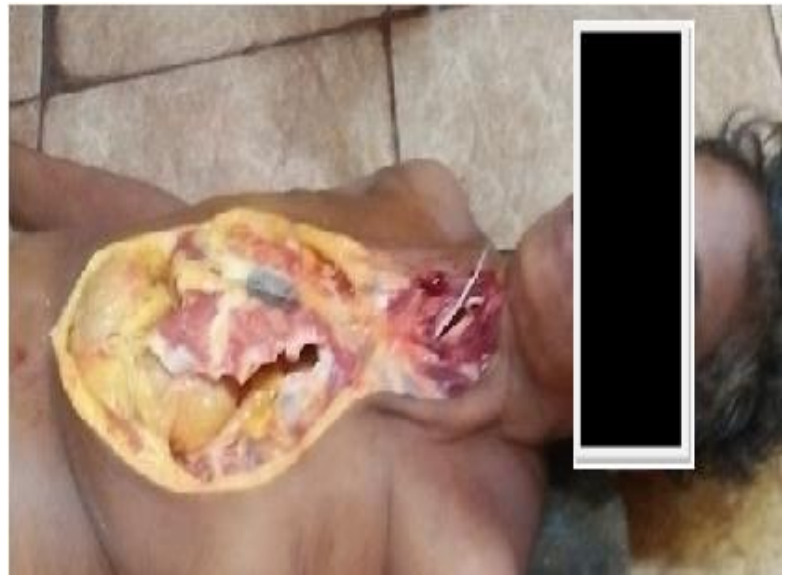

On Dissection: Brain \& Skull - Intact and Health: Adult round worms were found in trachea and both lungs were congested, Heart was normal. In abdomen, liver slightly enlarged size (1800 gm), gallbladder was enlarged, Adult round worm found in common bile duct obstructing the lumen. In trachea, large number of adult worms were seen (Picture 3). Stomach was full with adult round worms and without any food material (Picture 4). Both, kidneys were normal. Spleen was mildly enlarged. All body secretions were yellow coloured.

\section{Discussion}

Human acquire helminthic infection by ingestion of infected food, drink or raw vegetables. Children in rural areas and persons staying in unhygienic conditions are susceptible to infection of Round worms (Ascariasis Lumbricoides). Round worm is a nematode where necessary preventive measures are effective in controlling the infection. Primary preventive measure include proper hygiene, good sanitation, provision of safe drinking water, health education to the community, change in behavioural pattern and use of sanitary latrines are important preventing measures. Treatment of vegetable and garden crops with water containing 
iodine $^{(8)} 200 \mathrm{ppm}$ for 15 minutes will kill eggs and larvae. Secondary prevention includes effective drugs.

Mass treatment for determining in intervals of 2-3 months particularly where parasite is highly prevalent or protein energy malnutrition is very common. ${ }^{(7)}$

Global target is to eliminate morbidity due to soil transmitted helminthiasis in children by 2020 . The WHO strategy for control of soil transmitted helminth infection is to control morbidity through periodic treatment of at risk people living in endemic areas such as school children, women of child bearing age, adults who are at high risk occupation such as tea-pickers. Preventive measures must also take into account social and cultural circumstances prevailing in community. ${ }^{(7)}$

\section{Conclusion}

Round worm infestation is present globally, but more common in developing countries with poor personal hygiene. The Round worm (Ascariasis Lumbricoides) harm the host by depriving them of nutrition, intestinal or any other duct obstruction. Although fatality is rare in round worm infestation but in heavy infection adult worm can cause death by obstructing vital ducts/ tracts in the body of a person. Timely intervention in prevention of infection and treatment can prevent malnutrition as well as unfortunate fatality.

\section{References}

1. Agrawal Anil: Essentials of Forensic Medicine and Toxicology, $1^{\text {st }}$ Edition, 2014 (Page - 114).

2. Bailey and Love's: Short Practice of Surgery, 24 ${ }^{\text {th }}$ Edition, 2004 (Page- 159).

3. Bhat M. Sriram: Manual of Surgery, $5^{\text {th }}$ Edition, 2010 (Page-641).

4. C.P Baveja et al: Medical Parasitology, Third Edition, 2007, reprint 2016, (Page - 136, 137).

5. Hamson's Principle of Internal Medicine, $16^{\text {th }}$ Edition, 2005 (Page - 1257).

6. KSN Reddy: The Essentials of Forensic Medicine and Toxicology, $33^{\text {rd }}$ Edition (Page -150 ).

7. Park's Preventive and social Medicine, $24^{\text {th }}$ Edition, 2017 (Page - 257).

8. Paniker C.K Jayram, Text book of Medical Parasitology, $6^{\text {th }}$ Edition, 2007 (Page - 188).

9. R.L Ichhpujani et al: Medical Parasitology, $3^{\text {rd }}$ Edition, 2005 (Page -149).

10. Robbins and Cortans: Pathologic Basis of Disease, $7^{\text {th }}$ Edition, 2004 (Page - 902).

11. Tripathy K.D: Essentials of Medical Pharmacology, $5^{\text {th }}$ Edition, 2003 (Page - 760, 761). 